\title{
Cell Membrane Is a Major Locus for Ultraviolet B-induced Alterations in Accessory Cells
}

Jean Krutmann," Islam U. Khan," Robert S. Wallis, ${ }^{\ddagger}$ Fen Zhang, Elizabeth A. Rich, ${ }^{5}$ Jerrold J. Ellner," and Craig A. Elmets" Departments of ${ }^{*}$ Dermatology and ${ }^{\ddagger}$ Medicine, University Hospitals of Cleveland, Case Western Reserve University, Cleveland, Ohio 44106; and \$Department of Cell Biology and Anatomy, University of North Carolina-Chapel Hill, Chapel Hill, North Carolina 27599

\begin{abstract}
In vitro ultraviolet B (UVB) irradiation of human blood monocytes inhibits their accessory cell function for antigen- and mitogen-induced $T$ cell responses. These studies were designed to characterize the nature of the UVB-induced defect in human monocyte accessory cell function. Irradiated monocytes were deficient in their ability to serve as accessory cells for OKT3induced $T$ cell activation. In vitro exposure of monocytes to 100 $\mathrm{J} / \mathrm{m}^{2}$ UVB completely inhibited the $T$ cell proliferative response ( $51502 \mathrm{cpm}$, non-UVB-irradiated; 302 cpm, UVB-irradiated). Analysis of the accessory signals altered by UVB indicated that irradiated monocytes were incapable of binding to OKT3 molecules attached to the CD3 antigen on T cells. Provision of an alternative mechanism for binding of OKT3 molecules by attaching anti-mouse IgG to the bottom of microtiter wells completely restored accessory cell function. Further characterization of the defect demonstrated that UVB radiation did not deplete $\mathrm{p72}$ Fc receptors from the surface of irradiated monocytes. However, UVB exposure did produce a dose-dependent decrease in monocyte membrane expression of ICAM-1. It is proposed that UVB radiation leads to changes within the cell membrane that inhibit the ability of monocytes to express selected molecules necessary for binding of $T$ cells. (J. Clin. Invest. 1990. 85:1529-1536.) photoimmunology • antigen presentation - ultraviolet B radiation - ICAM-1 - monocytes
\end{abstract}

\section{Introduction}

Ultraviolet B radiation (UVB) ${ }^{1}(290-320 \mathrm{~nm})$ is a potent modulator of specific cell-mediated immune responses (1-3). UVB-irradiated mice are deficient in their ability to initiate immune responses to UVB-induced skin cancer (4), to contact sensitizing agents $(5-7)$ and to certain microorganisms $(8,9)$.

Address reprint requests to Dr. Elmets, Department of Dermatology, University Hospitals of Cleveland, 2074 Abington Road, Cleveland, OH 44106. Dr. Krutmann's current address is Universitats Hautklinik, Hauptstr. 7, D-7800 Freiburg i. Br., West Germany.

Received for publication 22 February 1988 and in revised form 3 October 1989.

1. Abbreviations used in this paper: aMIgG, anti-mouse IgG; FITCOKT3, FITC-conjugated OKT3 MAb; ICAM-1, intercellular adhesion molecule 1; MN (noUV), unirradiated human peripheral blood monocytes; $\mathrm{MN}(\mathrm{UV})$, human peripheral blood monocytes, irradiated in vitro with $100 \mathrm{~J} / \mathrm{m}^{2} \mathrm{UVB}$; UVB, ultraviolet B radiation.

J. Clin. Invest.

(c) The American Society for Clinical Investigation, Inc. 0021-9738/90/05/1529/08 $\$ 2.00$

Volume 85, May 1990, 1529-1536
These observations have been ascribed both to an inhibition in the function of antigen presenting cells responsible for activation of helper $\mathrm{T}$ lymphocytes $(5,10,11)$ and to the preservation of the antigen presenting function of cells (12) required for the activation of suppressor $T$ cell circuits $(13,14)$. This translates into excessive numbers of suppressor $T$ lymphocytes and deficient numbers of helper $\mathrm{T}$ lymphocytes in UVB-irradiated animals.

In humans, relatively modest doses of UVB delivered in vitro can inhibit the function of peripheral blood monocytes (MN) and epidermal Langerhans cells in accessory cell dependent assays of helper $T$ cell activation (15-17). The situation is somewhat more complex when humans receive this form of nonionizing radiation in vivo in that UVB exposure first inhibits antigen presentation by epidermal cells, but later augments that function (16). However, the augmented antigen presenting capacity that occurs later appears to result from immigration into the epidermis of $\mathrm{CDI}^{-} \mathrm{DR}^{+}$antigen presenting cells that are responsible for the preferential activation of $\mathrm{CD} 4+, 2 \mathrm{H} 4+\mathrm{T}$ cells (17). One function of CD4+, $2 \mathrm{H} 4+\mathrm{T}$ cells is to induce suppressor $\mathrm{T}$ cell formation.

The repeated observation that a decrease in the viability of UVB-irradiated cells is not a necessary precondition for the loss of antigen-presenting function has led to an examination of the accessory signals that are inhibited by UVB (18-22). There is some evidence to indicate that altered IL-1 production contributes to this effect $(21,22)$. However, the addition of exogenous IL-1 $(15,22)$ only partially reconstitutes the response when added to cultures containing UVB-irradiated antigen presenting cells. Other studies have implicated deficient antigen processing as an accessory signal altered by UVB (15, $18,20,21)$. This, too, does not appear to be the sole accessory cell deficit imposed by UVB since denatured antigen also fails to completely restore the $T$ cell proliferative response (23). Furthermore, a UVB-induced impairment in antigen processing is unlikely to be the only accessory deficit, because essentially identical doses of UVB inhibit monocyte accessory activity for mitogens, which are stimuli that are not processed (15).

This study was designed to further investigate the accessory cell defects that accompany UVB radiation exposure. We were particularly interested in effects on the cell membrane since this aspect of accessory function has not been investigated previously after UVB radiation. For this purpose, an accessory dependent system was employed in which OKT3 served as the mitogenic stimulus. In this system, MN have been shown to bind, via their surface membrane associated Fc receptors, to the Fc portion of OKT3 antibodies that have attached to the CD3 complex on $T$ cells $(24,25)$. They also secrete the soluble cytokine IL-1 (25-27). Neither major histocompatibility complex restriction nor a stimulus processing step is required for activation of $\mathrm{T}$ cells by OKT3. Our studies demonstrate that UVB has a major effect on cell membrane expression of the 
adhesion molecule ICAM-1, an additional signal provided by monocytes for $\mathrm{T}$ cell activation by OKT3.

\section{Methods}

Antibodies and cytokines. Both unconjugated and FITC-conjugated purified OKT3, and unconjugated OKT4 and OKT8 MAb, which identify the CD3, CD4, and CD8 differentiation antigens, respectively, and purified OKIa, which is a MAb to a framework determinant of the HLA-DR antigen, were purchased from Ortho Diagnostic Systems, Inc. (Raritan, NJ). The MAb FcR32, which binds to the high affinity p72 Fc receptor on human MN, was generously provided by Dr. P. M. Guyre, Department of Microbiology and Physiology, Dartmouth Medical School (Hanover, NH). Its properties have previously been described in detail (28). RR 1/1 MAb, which reacts with ICAM-1, was kindly provided by Dr. Robert Rothlein, Boehringer Ingelheim Pharmaceuticals, Inc. (Indianapolis, IN) (29). Affinity purified goat antimouse IgG (aMlgG,) was obtained from Cooper Biomedical, Inc. Malvern, PA. FITC-conjugated goat anti-mouse $\operatorname{IgG}\left(\mathrm{Fab}_{2}\right)$ was purchased from Tago, Inc. (Burlingame, CA) or Chemicon International (El Segundo, CA). Human recombinant IL-1 alpha and IL-1 beta were the gift of Dr. P. Lomedico, Hoffmann-La Roche (Nutley, NJ). The bioactivity of these cytokines was verified before use by adding them to cultures of mouse thymocytes in the mouse-thymocyte proliferation assay for IL-1. Recombinant human interferon gamma was purchased from Amgen Biologicals (Thousand Oaks, CA).

Purification of T lymphocytes. Peripheral blood mononuclear cells were obtained from the heparinized blood of healthy human volunteers by Ficoll-Hypaque (Pharmacia Fine Chemicals, Piscataway, NJ) density sedimentation. T-lymphocytes were depleted of accessory cells by a rigorous four-step purification procedure as described previously (30). Briefly, peripheral blood mononuclear cells were allowed to adhere to plastic tissue culture dishes (Falcon Labware, Oxnard, CA) for $1 \mathrm{~h}$. Plastic nonadherent cells were then placed on nylon-wool columns (Fenwall Laboratories, Deerfield, IL) for $\mathbf{4 5} \mathrm{min}$. Nylon-wool nonadherent cells were subsequently exposed to the lysosomotropic agent L-leucine-methyl-ester (Sigma Chemical Co., St. Louis, MO) for 40 min according to the method described by Thiele et al. (31). Finally, these $T$ cells were treated with a 1:50 dilution of OKIa and low toxicity rabbit complement (Cedarlane Laboratories Ltd., Hornby, Ontario). Treatment in this manner resulted in a T-lymphocyte population that, without the addition of exogenous accessory cells, was completely unresponsive to concanavalin A and OKT3. The number of Ia-positive cells was less than $0.5 \%$ as monitored on a FACS EPICS V fluorescence activated cell sorter (Coulter EPICS Division, Hialeah, FL), which was at the limit of sensitivity of the assay.

Preparation and UVB-irradiation of accessory cells. Accessory cells were prepared by gently scraping off and removing the plastic-adherent cells during the first step of the T-lymphocyte purification procedure. They were then centrifuged, resuspended in HBSS (KC Biological, Lenexa, KS), and counted. This population was $85-90 \%$ nonspecific esterase positive, and for the purposes of this paper will be called MN. Two $\times 10^{6} \mathrm{MN}$ in $1.5 \mathrm{ml}$ HBSS without phenol red were placed in 35 $\times 10 \mathrm{~mm}$ culture dishes (Falcon) and exposed to various doses of UVB from 4 FS20 sunlamp bulbs (Westinghouse Electrical Corp., Bloomfield, NJ). The UVB output was monitored by means of an IL 700 Research Radiometer and SEE 240 UVB Photodetector (International Light, Newburyport, MA) and was $\sim 12.2 \times 10^{-5} \mathrm{~J} / \mathrm{s} \mathrm{per} \mathrm{cm}^{2}$ at a tube to target distance of $22 \mathrm{~cm}$. To obtain an homogeneously irradiated cell population, culture dishes were gently shaken every $15 \mathrm{~s}$ during UVB exposure. MN were recovered from the dishes by scraping with a rubber policeman, centrifuged, resuspended in RPMI 1640 medium (Whittaker, Walkersville, MD) and counted. UV-irradiated [MN(UV)] and non-UV-irradiated MN [MN(no UV)] were treated in an identical fashion. Viability of irradiated $\mathrm{MN}$, as assessed by trypan blue exclusion was $>90 \%$ and did not differ from that of unirradiated cells during the 72 -h culture period.
OKT3-induced T cell blastogenesis. The MAb OKT3 served as the mitogenic stimulus. $1 \times 10^{5}$ highly purified $\mathrm{T}$ cells were co-cultured with $2 \times 10^{4}$ autologous, UV-irradiated MN and OKT3 in a total volume of $200 \mu \mathrm{l}$ of culture medium. OKT3 and MN were used in concentrations which, in preliminary experiments, gave optimal proliferative responses. Culture medium consisted of RPMI 1640, supplemented with $10 \%$ pooled human serum, penicillin $(10,000 \mathrm{U} / \mathrm{ml})$, streptomycin $(10,000 \mu \mathrm{g} / \mathrm{ml})$, L-glutamine $(2 \mathrm{mM})$, and Hepes buffer $(10 \mathrm{mM})$. In some experiments cells from a PPD reactive T cell line (1 $\times 10^{5}$ ) were used as responder cells instead of highly purified $\mathrm{T}$ cells (15). Cultures were set up in 96-well microtiter plates (Corning Glass Works, Corning, NY) and incubated for $72 \mathrm{~h}$ at $37^{\circ} \mathrm{C}$ in $5 \% \mathrm{CO}_{2}$ humidified air. All variables were performed in triplicate wells. $1.0 \mu \mathrm{Ci}$ of methyl- $\left[{ }^{3} \mathrm{H}\right]$ thymidine (New England Nuclear, Boston, MA) was added to each well for the last $18 \mathrm{~h}$ of culture. Wells were harvested onto glass filter paper using a Multiple Automatic Sample Harvester (M. A. Bioproducts, Walkersville, MD) and tritiated thymidine content per well assessed by scintillation spectrophotometry. Data were expressed as $\mathrm{cpm} \times 10^{-3} \pm \mathrm{SD}$.

Attachment of anti-mouse $\operatorname{IgG}$ to microtiter wells. The method of Walker et al. (32) was employed to attach anti-mouse IgG (aMIgG) to the bottom of 96 -well microtiter plates. Affinity purified goat aMIgG was diluted in Tris buffer at a pH of 9.5 to a final concentration of 5 $\mu \mathrm{g} / \mathrm{ml}$. $200 \mu \mathrm{l}$ of this solution was added to each well. Plates were incubated for $40 \mathrm{~min}$ at room temperature. Coated wells were then washed three times with PBS and once with PBS containing $1 \%$ fetal calf serum to remove unbound antibodies.

FC-receptor and ICAM-1 staining. Presence of p72 Fc-receptors on MN was assessed using the MAb FcR32. Staining of MN was performed as described by Anderson et al. (28). Briefly, $1 \times 10^{6} \mathrm{MN}$ were incubated for $2 \mathrm{~h}$ at $4^{\circ} \mathrm{C}$ in $50 \mu \mathrm{l}$ of MAb FcR32 diluted in RPMI 1640 supplemented with $10 \%$ fetal bovine serum. Cells were washed twice in HBSS with $0.3 \% \mathrm{BSA}$, resuspended and incubated for $2 \mathrm{~h}$ at $4^{\circ} \mathrm{C}$ in 100 $\mu$ of a 1:20 dilution of FITC-aMIgG. Cells were then fixed with $1 \%$ paraformaldehyde and stored at $4^{\circ} \mathrm{C}$ before analysis. Stained cells were analyzed on an EPICS V fluorescence activated cell sorter. Data are shown as histograms of $\log$ fluorescence intensity ( $x$-axis) and cell number ( $y$-axis) of $1 \times 10^{5}$ counted cells.

For ICAM-1 staining, RR1/1 was employed as the primary antibody at a concentration of $10 \mu \mathrm{g} / \mathrm{ml}$ for $30 \mathrm{~min}$ (29). Cells were washed and then stained with a 1:20 dilution of FITC-aMIgG (Chemicon International).

Cell-cluster formation assay. Cultures were set up as described for OKT3-induced T-lymphocyte blastogenesis, but in flat-bottom microtiter plates (Falcon Labware). Plates were centrifuged for 4 min at 500 $\mathrm{rpm}$ before incubation at $37^{\circ} \mathrm{C}$ in $5 \% \mathrm{CO}_{2}$ humidified air. Cultures were examined for cell-cluster formation after 0,12 , and $18 \mathrm{~h}$. One cell cluster was defined as an aggregation of 3 or more cells when examined under a tissue culture microscope (American Optical, Buffalo, NY). Preliminary experiments in which clusters were stained with monoclonal antibodies demonstrated that they contained both $T$ cells and monocytes. The number of clusters was determined at a magnification of 200 by examining six randomly chosen view fields using an ocular grid. Variables were set up in triplicate. No cluster formation could be detected in cultures without MN. However, cell clusters were detectable in cultures without OKT3, indicating that there was a component of OKT 3 independent cell to cell interaction. This non-OKT3 dependent cell cluster formation was always $<30 \%$ of that occurring in cultures containing OKT3. In some experiments, the monoclonal anti-ICAM- 1 antibody RR $1 / 1$ or an isotype control monoclonal antibody was added to cultures at a $1: 100(42 \mu \mathrm{g} / \mathrm{ml})$ or $1: 1,000$ dilution $(4.2 \mu \mathrm{g} / \mathrm{ml})$. Data are expressed as the mean number of clusters per $200 \times$ field.

\section{Results}

Effects of in vitro UVB irradiation on $M N$ accessory cell function for OKT3-induced $T$ cell proliferation. Our previous studies had shown that in vitro exposure of MN to UVB radiation 
resulted in an inability of those cells to act as stimulator cells in accessory cell dependent $T$ lymphocyte proliferation assays for the soluble antigen tetanus toxoid and for the mitogen PHA (15). In the experiments presented here (Table I and Fig. 1), we examined whether the inhibitory effect of UVB on accessory function extended to assays in which OKT3 served as the mitogenic stimulus. Fig. 1 shows that a dose dependent decrease in $\mathrm{T}$ cell proliferation resulted when $\mathrm{MN}$ were exposed to various doses of UVB $\left(0-100 \mathrm{~J} / \mathrm{m}^{2}\right)$. The UVB doses were not lethal for $\mathrm{MN}$ over the entire duration of the culture period, as assessed by trypan blue exclusion. Similar results were obtained when the responding cells were $T$ lymphocytes from a PPD-specific T cell line that proliferated in response to OKT3 as well (data not shown). Furthermore, no inhibition of proliferation was observed in mixing studies in which $M N(U V)$ were placed in culture with $\mathrm{MN}$ (no UV), OKT3, and T cells (data not shown), indicating that the defect in accessory cell function following UVB exposure was intrinsic to the irradiated cell population. Thus, similar to its effect on the accessory function for PHA and for soluble antigen, UVB inhibited the function of accessory cells required for OKT3-induced T cell proliferation (15).

Effects of UVB irradiation on $M N$-derived accessory signals required for OKT3-induced T cell proliferation. The accessory signals required for activation of resting $T$-cells by antiCD3 antibodies are well-defined. Accessory cells secrete the cytokine IL-1 (23-25) and they provide an immobile matrix to which OKT 3 molecules attached to $T$ lymphocytes are able to bind $(24,25)$. The finding that UVB inhibited the function of accessory cells in this system suggested that it might be an excellent model for study of the effects of UVB on specific accessory signals.

In previous studies we had shown that UVB-irradiation of MN was associated with a greater than $95 \%$ reduction in their ability to produce IL-1 (15). Our initial attempts to reconstitute the accessory function of $\mathrm{MN}(\mathrm{UV})$ consisted of adding exogenous IL-1 to cultures. Neither recombinant IL- $1 \alpha$ nor IL- $1 \beta$, was able to provide even partial reconstitution of the proliferative response when $\mathrm{MN}(\mathrm{UV})$ were used as the stimulator cells (Table II). Although the data presented in Table II employed 10 U of IL- $1 \alpha$ and IL- $1 \beta$, essentially identical results were obtained with a wide range of IL-1 doses (0.1-100 U).

Table I. Inhibition of OKT3-induced T Lymphocyte Proliferation by In Vitro Exposure to UVB Radiation

\begin{tabular}{|c|c|c|}
\hline \multirow[b]{2}{*}{ Cultures containing } & \multicolumn{2}{|c|}{ Proliferative response } \\
\hline & Exp. 1 & Exp. 2 \\
\hline & \multicolumn{2}{|c|}{$\left(\mathrm{cpm} \times 10^{-3}\right) \pm S D$} \\
\hline $\mathrm{T}$ cells & $358 \pm 89$ & $180 \pm 6$ \\
\hline $\mathrm{T}$ cells $+\mathrm{OKT} 3$ & $509 \pm 111$ & $217 \pm 25$ \\
\hline $\mathrm{T}$ cells $+\mathrm{OKT} 3+\mathrm{MN}($ no UV) & $51,502 \pm 4,831$ & $52,240 \pm 2,100$ \\
\hline \multicolumn{3}{|l|}{$\mathrm{T}$ cells $+\mathrm{OKT} 3+\mathrm{MN}$} \\
\hline$\left(100 \mathrm{~J} / \mathrm{m}^{2} \mathrm{UV}\right)$ & $302 \pm 33$ & $472 \pm 141$ \\
\hline $\mathrm{T}$ cells $+\mathrm{MN}$ (no UV) & $430 \pm 75$ & $459 \pm 99$ \\
\hline $\mathrm{T}$ cells $+\mathrm{MN}\left(100 \mathrm{~J} / \mathrm{m}^{2}\right)$ & $282 \pm 38$ & $319 \pm 70$ \\
\hline
\end{tabular}

T lymphocytes $\left(1 \times 10^{5}\right)$ were cultured with or without OKT3 and either MN (no UV) or MN $\left(100 \mathrm{~J} / \mathrm{m}^{2}\right)$ for $72 \mathrm{~h}$ as described in Methods.

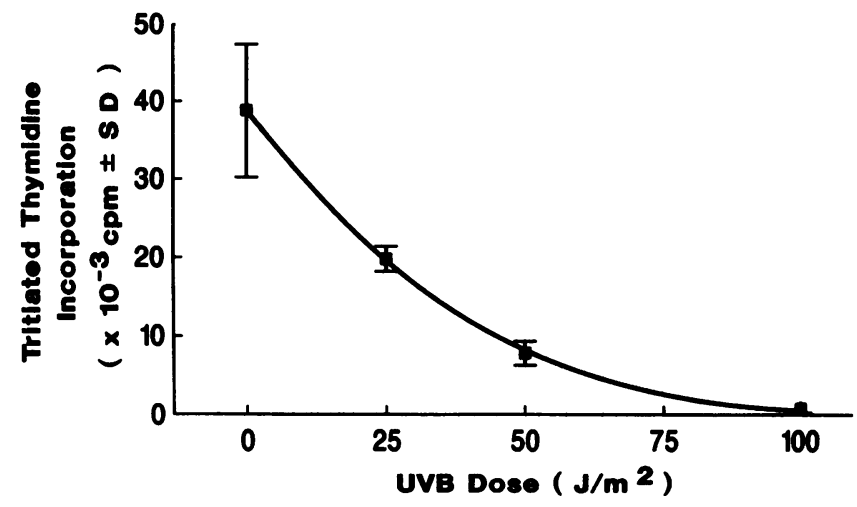

Figure 1. Dose-dependent inhibition of OKT3-induced T cell proliferation by UVB irradiation of MN. MN were exposed in vitro to various doses of UVB $\left(0-100 \mathrm{~J} / \mathrm{m}^{2}\right)$ and then co-cultured with autologous, accessory cell-dependent $\mathrm{T}$ lymphocytes as described in Table $\mathrm{I}$.

The inability of biologically active, exogenous IL-1 to overcome the UVB-induced defect in accessory cells indicated that altered IL-1 production was not the sole accessory cell signal modulated by UVB.

Because Fc receptor-mediated binding to the antibody molecule represented another accessory signal required for $T$ cell activation by OKT3, studies were next performed to analyze the effects of UVB on this monocyte-derived activity. This was assessed in a cell binding assay in which the number of clusters of $T$ cells around $M N(U V)$ was compared to clusters of $T$ cells around $M N($ no $U V)$. Table III shows a representative experiment. No cell clusters were detected in any culture at 0 h. A significant number formed after $12 \mathrm{~h}$, and this increased further after $18 \mathrm{~h}$ (see also Fig. $2 A$ ). Thus, proliferation in cultures with highly purified T cells, MN(no UV) and OKT3 was accompanied by an increase in cell cluster formation. Cluster formation was strictly dependent on the presence of $\mathrm{MN}$; no clusters formed in cultures with $\mathrm{T}$ cells and OKT 3 or $\mathrm{T}$ cells alone. A small number of cell clusters formed in cultures containing $\mathrm{T}$ cells and $\mathrm{MN}$ in the absence of OKT3. The data in Table III demonstrate that a dose-dependent inhibition of cell cluster formation occurred when $\mathrm{MN}$ were exposed to UVB doses ranging from 0 to $100 \mathrm{~J} / \mathrm{m}^{2} .100 \mathrm{~J} / \mathrm{m}^{2}$ was sufficient to completely inhibit cluster formation (Fig. $2 B$ and Table III). The UVB doses that inhibited cluster formation

Table II. Failure of Exogenous IL-1 to Reconstitute Accessory Cell Activity of $M N(U V)$

\begin{tabular}{cc}
\hline Cultures containing & Proliferative response \\
\hline & $\left(c p m \times 10^{-3}\right) \pm S D$ \\
T + MN (no UV) + OKT3 & $89,778 \pm 2,150$ \\
T + MN (UV) + OKT3 & $1,298 \pm 206$ \\
T + MN (UV) + OKT3 + IL-1 $\alpha$ & $978 \pm 242$ \\
T + MN (UV) + OKT3 + IL-1 $\beta$ & $997 \pm 341$ \\
\hline
\end{tabular}

Cultures were prepared as described in Table I. $10 \mathrm{U}$ of biologically active, human recombinant IL- $1 \alpha$ or IL- $1 \beta$ were added. IL- $1 \alpha$ and IL-1 $\beta$ did not augment the proliferative activity of cultures containing MN (no UV) or cultures containing no MN. 
Table III. Inhibition of OKT3-induced Cell Cluster Formation by UVB Radiation

\begin{tabular}{cccccc}
\hline & & & \multicolumn{3}{c}{ Number of cell clusters } \\
\cline { 4 - 6 } OKT3 & MN & UVB dose & $0 \mathrm{~h}$ & $12 \mathrm{~h}$ & $18 \mathrm{~h}$ \\
\hline & & $J / m^{2}$ & \multicolumn{3}{c}{ (Mean $\pm S D)$} \\
+ & + & 0 & $0.0 \pm 0.0$ & $24.3 \pm 3.8$ & $33.3 \pm 4.3$ \\
+ & + & 25 & $0.0 \pm 0.0$ & $8.3 \pm 2.5$ & $10.3 \pm 2.5$ \\
+ & + & 50 & $0.0 \pm 0.0$ & $2.6 \pm 1.5$ & $1.6 \pm 0.6$ \\
+ & + & 100 & $0.0 \pm 0.0$ & $1.0 \pm 1.0$ & $0.7 \pm 0.6$ \\
- & - & - & $0.0 \pm 0.0$ & $0.0 \pm 0.0$ & $\mathrm{ND}$ \\
+ & - & 0 & $0.0 \pm 0.0$ & $0.3 \pm 0.6$ & $\mathrm{ND}$ \\
- & + & 0 & $0.0 \pm 0.0$ & $5.0 \pm 1.4$ & $10.0 \pm 2.6$
\end{tabular}

T lymphocytes, MN $\left(0-100 \mathrm{~J} / \mathrm{m}^{2}\right)$ and OKT3 were cultured in flatbottom microtiter plates and number of cell clusters determined after 0,12 , and $18 \mathrm{~h}$ incubation at $37^{\circ} \mathrm{C}$ as described in Methods.

were identical to those that produced inhibition of $\mathrm{T}$ cell blastogenesis observed in Table $I$. These results indicate that $\mathrm{MN}(\mathrm{UV})$ were unable to form a physical interaction with the responding lymphocyte population.

We reasoned that if an alternative source for binding of the OKT3 molecule was present, restoration of the proliferative response might be observed. This was performed by attaching anti-mouse IgG molecules to the bottom of microtiter wells and adding purified T cells, OKT3 antibody and UVB-irradiated monocytes. Representative experiments are shown in Table IV. Cultures containing MN(no UV) showed a normal proliferative response (line $a$ ), which was reduced to background levels when $\mathrm{MN}$ were exposed in vitro to $100 \mathrm{~J} / \mathrm{m}^{2}$ UVB (line $b$ ). Attachment of aMIgG to the bottom of microtiter wells in cultures with MN(UV) completely restored proliferation (line $c$ ). This was a consistent and reproducible finding $(n=6)$. It has been demonstrated that immobilization of antiCD3 antibodies is sufficient to induce proliferation of purified resting $T$ lymphocytes $(24,31,33,34)$ and this observation was confirmed in these experiments (line $e$ ). Restoration could not be achieved when OKT4 or OKT8 was added to cultures instead of OKT3. When soluble aMIgG was added to cultures in lieu of using it to coat microtiter wells, no reconstitution of blastogenesis in cultures with $\mathrm{MN}(\mathrm{UV})$ occurred, suggesting that an immobilized matrix was required for proliferation (35, 36). Addition of biologically active recombinant IL-1 alpha to cultures with T-lymphocytes, OKT3, MN(UV) and attached aMIgG failed to further augment the response (data not shown). Taken together, these results suggest that the primary effect of UVB was to inhibit the interaction between $T$ cells and $\mathrm{MN}$, and that by providing an alternative mechanism for binding with solid-phase bound aMIgG, T lymphocyte proliferation could be reestablished.

Effect of $U V B$ radiation on the surface membrane expression of $M N$ receptors involved in binding to $T$ cells. OKT3 antibodies bind to the p72 Fc receptor, and it is through this receptor that monocytes mediate their binding function (37, 38). The next series of studies investigated whether UVB irradiation of monocytes depleted or inhibited the expression of this type of Fc receptor. This was examined by determining the reactivity of $M N(U V)$ with monoclonal antibody FcR32, whose reactivity is specific for the p72 Fc receptor (28). Fluorescence intensity and number of stained MN(UV) was compared to that of $\mathrm{MN}($ no UV) immediately after UVB exposure and after a 24-h incubation period. As shown in Fig. 3, there was no difference in the number of UV-irradiated or unirradiated $\mathrm{MN}$ at either time point nor was there a detectable difference in fluorescence intensity between the two cell populations. Thus, an inability of MN(UV) to bind OKT3 molecules was not due to a lack of p72 Fc receptors.

Because MAb32 does not recognize the ligand binding site of the p72 Fc receptor (28), it was possible that although the p72 Fc receptor was present on the monocyte surface it was unable to bind to the OKT3 molecule. To exclude this possibility, the binding of FITC-conjugated OKT3 antibodies was determined cytofluorometrically with a window selecting for the monocyte population. No difference in binding of FITCOKT 3 between $M N($ no $U V)$ and $M N(U V)$ could be detected immediately after UVB exposure or after 24,48 , or $72 \mathrm{~h}$.

Monocytes express ICAM-1 on their cell surface which binds to LFA-1 on the surface of T cells $(29,39)$. This receptor ligand interaction provides a stimulus independent mechanism for $\mathrm{T}$ cell binding to monocytes. Since alterations in Fc receptor expression or function did not appear to be responsible for the inability of $\mathrm{T}$ lymphocytes to bind to monocytes, studies were carried out to determine whether ICAM-1 expression was necessary for OKT3-induced $\mathrm{T}$ cell binding and proliferation, and, if so, whether monocyte expression of

Table IV. Restoration of OKT3-induced T Cell Proliferation in Cultures with MN (UV) by the Addition of Immobilized MIgG

\begin{tabular}{|c|c|c|c|c|c|c|c|}
\hline \multirow[b]{2}{*}{ Panel } & \multicolumn{4}{|c|}{ Additions to cultures } & \multicolumn{3}{|c|}{ Proliferative response } \\
\hline & aMIgG & OKT3 & MN (no UV) & MN (UV) & Exp. 1 & Exp. 2 & Exp. 3 \\
\hline $\mathbf{a}$ & - & + & + & - & $21,983 \pm 2,089$ & $59,697 \pm 10,558$ & $55,630 \pm 15,659$ \\
\hline b & - & + & - & + & $201 \pm 39$ & $552 \pm 132$ & $350 \pm 30$ \\
\hline c & + & + & - & + & $34,672 \pm 6,422$ & $77,847 \pm 5,611$ & $50,442 \pm 15$ \\
\hline d & + & - & - & - & ND & $255 \pm 14$ & $310 \pm 15$ \\
\hline e & + & + & - & - & $23,871 \pm 749$ & $48,642 \pm 10,912$ & $44,763 \pm 9,886$ \\
\hline f & - & - & - & - & $354 \pm 154$ & $486 \pm 109$ & ND \\
\hline
\end{tabular}

Cultures were prepared as described in Table I. They were plated in microtiter wells, that had been coated with aMIgG or that had been left uncoated, as described in Methods. UVB dose was $100 \mathrm{~J} / \mathrm{m}^{2}$. 

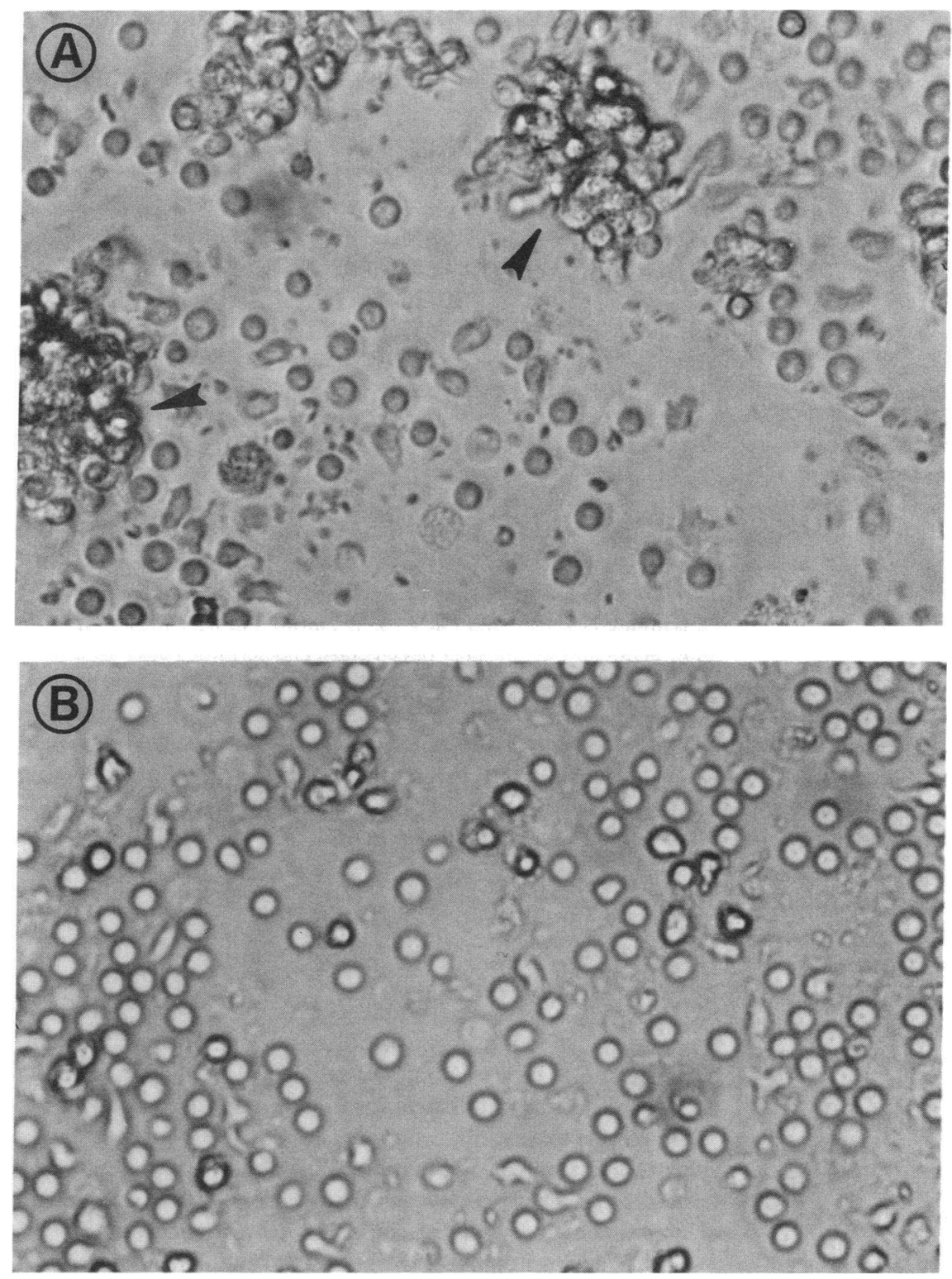

Figure 2. Photomicrographs $(\times 200)$ of cultures containing $\mathrm{T}$ cells, $\mathrm{OKT} 3$ and $\mathrm{MN}(\mathrm{no}$ $\mathrm{UV})(A)$ or $\mathrm{MN}(\mathrm{UV})(B)$. Arrows in $A$ indicate cell clusters.

ICAM-1 was affected by UVB exposure. When the antiICAM-1 antibody RR 1/1 was added continuously to cultures containing unirradiated monocytes, $\mathrm{T}$ cells and OKT3, OKT3-induced $\mathrm{T}$ cell proliferation was inhibited by greater than $80 \%$ (Table V). Isotype specific control antibodies did not affect the $T$ cell proliferative response (data not shown). In cell binding assays, the addition of anti-ICAM-1 antibodies inhibited the development of clusters around unirradiated monocytes (Table VI). Isotype specific monoclonal antibodies did not inhibit binding of $\mathrm{T}$ cells to monocytes (data not shown). The results of these experiments indicated that ICAM-1 expression was essential for $\mathrm{T}$ cell interactions with monocytes in the OKT3 assay.

To assess the effects of UVB on ICAM-1 expression, monocytes were UV-irradiated, incubated overnight, and then stained with the anti-ICAM-1 monoclonal antibody. In contrast to the lack of an effect on Fc receptor expression, UVB irradiation of monocytes produced a dose-dependent decrease in ICAM-1 expression (Fig. 4). $100 \mathrm{~J} / \mathrm{m}^{2} \mathrm{UVB}$ inhibited
ICAM-1 expression by $82 \%$, indicating that UVB radiation had a major effect on MN surface membrane expression of ICAM-1.

\section{Discussion}

Our data indicate that UVB radiation modifies monocyte cell membrane function. With respect to accessory function for OKT3-induced $T$ cell activation, this was manifest as an inability of UV-irradiated monocytes to provide the necessary signals for $\mathrm{T}$ cell proliferation. Direct cell to cell contact between $\mathrm{MN}(\mathrm{UV})$ and $\mathrm{T}$ cells was markedly decreased. T lymphocyte proliferation could be completely restored by adding immobilized goat anti-mouse IgG to cultures thereby providing an alternative source for binding of the Fc portion of the OKT3 molecule.

The UVB-induced inhibition of accessory function was associated with a decrease in MN surface membrane ICAM-1 expression. Recent interest has focused on receptor ligand in- 

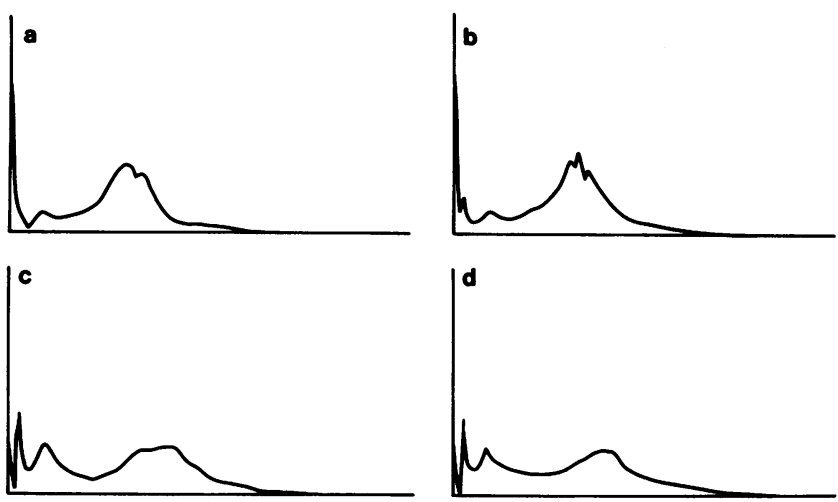

Figure 3. Normal numbers of p72 Fc receptors on the surface of UVB-irradiated MN. MN(UV) were exposed in vitro to $100 \mathrm{~J} / \mathrm{m}^{2}$ UVB. Cells were stained with MAb FcR32 and FITC-anti-mouse IgG immediately after UVB exposure $(0 \mathrm{~h})$ or after $24 \mathrm{~h}$ incubation in complete medium supplemented with $10 \%$ PHS. Histograms of cell-number ( $y$-axis) and fluorescence intensity ( $x$-axis) are $(a)$ $\mathrm{MN}$ (no UV) stained at $\mathbf{0} \mathrm{h},(b) \mathrm{MN}(\mathrm{UV})$ stained at $0 \mathrm{~h},(c) \mathrm{MN}$ (no UV) stained at $24 \mathrm{~h},(d) \mathrm{MN}(\mathrm{UV})$ stained at $24 \mathrm{~h}$.

teractions between $\mathrm{T}$ cells and monocytes as additional accessory signals involved in antigen- and mitogen-induced activation of $T$ lymphocytes (40-42). In particular, $T$ cells express LFA-1 and CD2 on their cell surface which bind to ICAM-1 and LFA-3, respectively, on monocytes. $T$ cell proliferative responses to $P P D$ have been shown to be inhibited by antibodies to ICAM-1 (40). The finding in this study that UVB radiation inhibited ICAM-1 expression on monocytes provides evidence to suggest that this form of radiant energy impairs accessory cell- $T$ cell interactions that lead to $T$ cell activation through an effect on this molecule. It is also possible that other membrane proteins including other adhesion molecules could be additional contributing factors to the deficient binding of $T$ cells to UVB-irradiated monocytes.

The effect of UVB radiation on IL-1 production by MN and keratinocytes is controversial. While some investigators

Table V. Inhibition of OKT3-induced T Lymphocyte Proliferation by Anti-ICAM-1 Antibodies

\begin{tabular}{lcc}
\hline & \multicolumn{2}{c}{ Proliferative response } \\
\cline { 2 - 3 } Cultures containing & \multicolumn{2}{c}{$c p m \times 10^{-3} \pm S D$} \\
& $268 \pm 167$ & $363 \pm 384$ \\
T cells & $201 \pm 73$ & $443 \pm 491$ \\
T cells + OKT3 & & \\
T cells + OKT3 + MN (no UV) & $116,584 \pm 1,049$ & $81,838 \pm 6,786$ \\
T cells + OKT3 + MN (no UV) & & \\
+ ICAM-1 (1:100) & $35,143 \pm 866$ & ND \\
T cells + OKT3 + MN (no UV) & & \\
+ ICAM-1 (1:1,000) & ND & $49,979 \pm 6,758$ \\
T cells + MN (no UV) & $939 \pm 116$ & $1,012 \pm 743$ \\
MN & $333 \pm 139$ & $198 \pm 171$
\end{tabular}

T lymphocytes $\left(1 \times 10^{5}\right)$ were cultured with or without OKT3 and MN (no UV) for $72 \mathrm{~h}$ as described under Methods. ICAM-1 was added at the indicated dilution.
Table VI. Inhibition of OKT3-induced Cell Cluster Formation by Anti-ICAM-1 Antibodies

\begin{tabular}{ccccc}
\hline & & & \multicolumn{2}{c}{ Number of cell clusters } \\
\cline { 4 - 5 } OKT3 & MN & Antibody added & Exp. 1 & Exp. 2 \\
\hline+ & + & - & $14.4 \pm 6.7$ & $29.3 \pm 4.8$ \\
+ & + & ICAM-1 & $1.1 \pm 1.2$ & $\mathrm{ND}$ \\
& & $(1: 100$ dilution $)$ & & \\
+ & + & ICAM-1 & $\mathrm{ND}$ & $11.7 \pm 1.5$ \\
& & $(1: 1,000$ dilution $)$ & & \\
- & - & - & $0.1 \pm 0.2$ & $0.2 \pm 0.5$ \\
+ & - & - & $0.0 \pm 0.0$ & $0.0 \pm 0.0$ \\
- & + & - & $3.7 \pm 2.0$ & $7.4 \pm 2.2$ \\
- & + & ICAM-1 & $0.5 \pm 0.7$ & $\mathrm{ND}$ \\
& & $(1: 100$ dilution $)$ & & \\
- & + & ICAM-1 & & \\
& & $(1: 1,000$ dilution $)$ & ND & $3.6 \pm 2.2$ \\
\hline
\end{tabular}

T lymphocytes, MN and OKT3 were cultured in flat-bottom microtiter plates and the number of cell clusters determined after $16 \mathrm{~h}$ incubation at $37^{\circ} \mathrm{C}$ as described in Methods.

have found that UVB-irradiated murine peritoneal exudate cells (43) and keratinocytes produce increased amounts of IL-1 and contain increased levels of IL-1 mRNA (44) others have found precisely the opposite $(15,19,21)$. The reason for such divergent results is unclear although differences in the UVB doses actually delivered may provide a partial explanation. In our hands, supernatants from MN exposed to $50-200 \mathrm{~J} / \mathrm{m}^{2}$ UVB contain reduced amounts of IL-1 (15). Nonetheless, exogenous IL-1 failed to reconstitute the T cell proliferative response to OKT3. The ability of other investigators to partially reconstitute immunological responsiveness with this cytokine may be due to a small number of accessory cells contaminating the responding cell population. This appears likely since less rigorous procedures were used in these studies to obtain an accessory cell dependent responder cell population $(20,21$, 22). When immobilized aMIgG was provided to bind OKT3 attached to $\mathrm{T}$ cells, complete restoration of the response occurred, which could not be further increased by the addition of IL-1. These results might suggest that IL-1 is not required for T

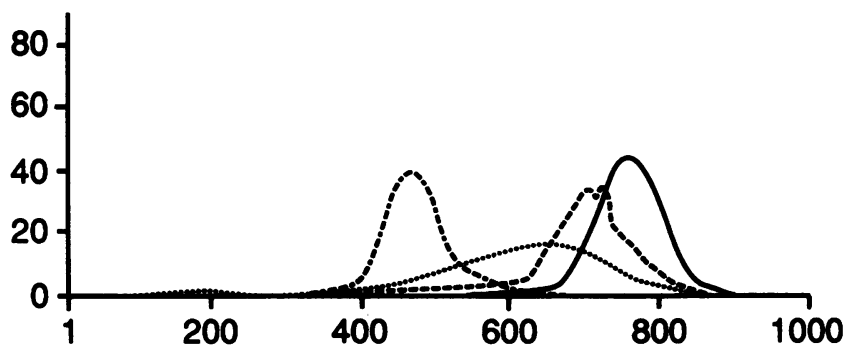

Figure 4. Deficient ICAM-1 expression on the surface of UVB-irradiated MN. Cells were stained with MAb RR1/1 as described in Methods and were then examined by flow cytometry. The $x$-axis represents the $\log$ of the fluorescence intensity on arbitrary units. The $y$ axis represents the cell number. - - , negative control; $\cdots ., \mathrm{MN}$ exposed to $100 \mathrm{~J} / \mathrm{m}^{2} \mathrm{UVB} ;$--.--, MN exposed to $50 \mathrm{~J} / \mathrm{m}^{2} ;-$, , MN exposed to $0 \mathrm{~J} / \mathrm{m}^{2} \mathrm{UVB}$. 
cell activation by OKT3. However, it is possible that the target of IL-1 in this assay system is the accessory cell rather than the responding $\mathrm{T}$ lymphocyte. This would be consistent with the findings of Koide and Steinman (45) who reported that the accessory function of dendritic cells was markedly enhanced by preculture with IL-1, indicating a direct effect of this cytokine on the dendritic cell population. If that is the case, then an additional mechanism by which UVB might exert its effect on cells would be by inhibiting their response to soluble mediators. In this regard, we have shown that human natural killer cells are less responsive to IL-2 and interferon-gamma following UVB exposure (46). This, too, could be mediated by UVB-induced inhibition of signals transmitted through the membrane.

In summary, the present study demonstrates that UVB-induced modulation of human MN accessory cell function is associated with a decrease in expression of $\mathrm{MN}$ membrane ICAM-1. To our knowledge, this is the first report describing the cell membrane as a major target structure in UVB effects on accessory cells. Further studies are under way to examine whether the cell membrane is the actual chromophore and which membrane components are altered by UVB.

\section{Acknowledgments}

We greatly appreciate the helpful discussions and critical reviews of the manuscript by Dr. Ken Jacobson, Dr. Paul M. Guyre, and Dr. Thomas Luger. We also acknowledge the excellent technical assistance of $\mathrm{Mr}$. Gregory Urda and the careful preparation of the manuscript by Ms. Carol Highsmith.

This work was supported by grants R01-AR32593, R01-CA48763, and P30-CA43703 from the National Institutes of Health (NIH), KR871-3 from the Deutsche Forschungsgemeinschaft, West Germany, and R-813324 from the U. S. Environmental Protection Agency. Dr. Elmets is the recipient of a Research Career Development Award from the NIH (AR01765).

\section{References}

1. Krutmann, J., and C. A. Elmets. 1988. Recent studies on mechanisms in photoimmunology. Yearly review. Photochem. Photobiol. 48:787-798.

2. Granstein, R. D. 1986. Photoimmunology. In Dermatology in General Medicine. T. B. Fitzpatrick, A. Z. Eisen, K. Wolff, H. Z. Eisen, and K. F. Austin, editors. McGraw-Hill Book Co., New York. Vol. 1, 1458-1470.

3. Daynes, R. A., H. T. Chung, B. Robertson, L. K. Roberts, and W. E. Samlowski. 1986. Immunomodulation by ultraviolet radiation. In Effects of changes in stratospheric ozone and global climate. J. G. Titus, editor. United States Environmental Protection Agency, Washington, DC Vol. 2. 63-86.

4. Kripke, M. L. 1974. Antigenicity of murine skin tumors induced by ultraviolet light. J. Natl. Cancer Inst. 53:1333-1336.

5. Toews, G. B., P. R. Bergstresser, J. W. Streilein, and S. Sullivan. 1980. Epidermal Langerhans cell density determines whether contact hypersensitivity or unresponsiveness follows skin painting with DNFB. J. Immunol. 124:445-453.

6. Jessup, J. M., N. Hanna, E. Palaszynski, and M. L. Kripke. 1978. Mechanism of depressed reactivity to dinitrochlorobenzene and ultraviolet-induced tumors during ultraviolet carcinogenesis in BALB/c mice. Cell. Immunol. 38:105-115.

7. Elmets, C. A., M. J. LeVine, and D. R. Bickers. 1985. Action spectrum studies for induction of immunologic unresponsiveness to dinitrofluorobenzene following in vivo low dose ultraviolet radiation. Photochem. Photobiol. 42:391-397.
8. Howie, S., M. Norval, and J. Maingay. 1986. Exposure of low dose ultraviolet radiation suppresses delayed-type hypersensitivity to Herpes simplex virus in mice. J. Invest. Dermatol. 86:125-128.

9. Giannini, S. H. 1986. Suppression of pathogenesis in cutaneous Leishmaniasis by UV radiation. Infect. Immun. 51:838-843.

10. Greene, M. I., M. S. Sy, M. Kripke, and B. Benacerraf. 1979. Impairment of antigen-presenting cell function by ultraviolet radiation. Proc. Natl. Acad. Sci. USA. 76:6591-6595.

11. Sauder, D. N., K. Tamaki, A. N. Moshell, H. Fujiwara, and S. I. Katz. 1981. Induction of tolerance to topically applied TNCB using TNP-conjugated ultraviolet-irradiated epidermal cells. J. Immunol. 127:261-265.

12. Granstein, R. D., A. Lowy, and M. I. Greene. 1984. Epidermal antigen-presenting cells in activation of suppression. Identification of a new functional type of ultraviolet radiation resistant epidermal cell. $J$. Immunol. 132:563-565.

13. Elmets, C. A., P. R. Bergstresser, R. E. Tigelaar, P. J. Wood, and J. W. Streilein. 1983. Analysis of the mechanism of unresponsiveness produced by haptens painted on skin exposed to low dose ultraviolet radiation. J. Exp. Med. 158:781-794.

14. Spellman, C. W., and R. A. Daynes. 1977. Modification of immunological potential by ultraviolet radiation. Transplantation. 24:120-126.

15. Rich, E. A., C. A. Elmets, H. Fujiwara, R. S. Wallis, and J. J. Ellner. 1987. Deleterious effects of ultraviolet-B radiation on accessory function of human blood adherent mononuclear cells. Clin. Exp. Immunol. 70:116-126.

16. Cooper, K. D., P. Fox, G. Neises, and S. I. Katz. 1985. Effects of ultraviolet radiation on human epidermal cell alloantigen presentation: initial depression of Langerhans cell-dependent function is followed by the appearance of $\mathrm{T}^{-} \mathrm{Dr}^{+}$cells that enhance epidermal alloantigen presentation. J. Immunol. 134:129-137.

17. Baadsgard, O., D. Fox, and K. D. Cooper. 1988. Human epidermal cells from ultraviolet light-exposed skin preferentially activate autoreactive $\mathrm{CD}^{+} 2 \mathrm{H}^{+}$suppressor-inducer lymphocytes and $\mathrm{CD}^{+}$ suppressor/cytotoxic lymphocytes. J. Immunol. 140:1738-1744.

18. Germain, R. N. 1981. Accessory cell stimulation of T cell proliferation requires active antigen processing. Ia-restricted antigen presentation, and a separate nonspecific 2 nd signal. J. Immunol. 127:1964-1966.

19. Stingl, G., L. A. Gazze-Stingl, and W. Aberer. 1981. Antigen presentation by murine epidermal Langerhans cells and its alteration by ultraviolet B light. J. Immunol. 127:1707-1713.

20. Stingl, L. A., D. N. Sauder, M. Ijima, K. Wolff, H. Pehamberger, and G. Stingl. 1983. Mechanism of UVB-induced impairment of the antigen-presenting capacity of murine epidermal cells. J. Immunol. 130:1586-1591.

21. Jakway, J. P., and E. M. Shevach. 1983. Stimulation of T-cell activation by UV-treated, antigen-pulsed macrophages. Evidence for a requirement for antigen processing and interleukin 1 secretion. Cell. Immunol. 80:151-162.

22. Sauder, D. N., F. P. Noonan, E. C. DeFabo, and S. I. Katz. 1983. Ultraviolet radiation inhibits alloantigen presentation by epidermal cells: partial reversal by the soluble epidermal cell product, epidermal cell-derived thymocyte-activating factor (ETAF). J. Invest. Dermatol. 80:485-489.

23. Shimada, S., Z. Kovac, R. H. Schwartz, and S. I. Katz. 1985. Effect of ultraviolet radiation on antigen presentation. Clin Res. 33:531a. (Abstr.)

24. Ceuppens, J. L., F. J. Bloemmen, and J. P. van Wauwe. 1985. T cell unresponsiveness to the mitogenic activity of OKT3 antibody results from a deficiency of monocyte Fc receptors for murine IgG2a and inability to cross-link the T3-Ti complex. J. Immunol. 135:3882-3886.

25. Palacios, R. 1985. Mechanisms by which accessory cells contribute in growth of resting $\mathrm{T}$ lymphocytes initiated by OKT3 antibody. Eur. J. Immunol 15:645-651.

26. Williams, J. M., D. Deloria, J. A. Hansen, C. A. Dinarello, R. Loertscher, H. M. Shapiro, and T. B. Strom. 1985. The events of 
primary $\mathrm{T}$ cell activation can be staged by use of sepharose-bound anti-T3(64.1) monoclonal antibody and purified interleukin 1. J. Immunol. 135:2249-2255.

27. Schwab, R., M. K. Crow, C. Russo, and M. E. Weksler. 1985. Requirements for $\mathrm{T}$ cell activation by OKT3 monoclonal antibody: role of modulation of T3 molecules and interleukin 1. J. Immunol. 135:1714-1718.

28. Anderson, C. L., P. M. Guyre, J. C. Whitin, D. H. Ryan, R. J. Looney, and M. W. Fanger. 1986. Monoclonal antibodies to Fc receptors for IgG on human mononuclear phagocytes. J. Biol. Chem. 261:12856-12864.

29. Rothlein, R., M. L. Dustin, S. D. Marlin, and T. A. Springer. 1986. A human intercellular adhesion molecule (ICAM-1) distinct from LFA-1. J. Immunol. 137:1270-1274.

30. Krutmann, J., M. Athar, D. B. Mendel, I. U. Khan, P. M. Guyre, H. Mukhtar, and C. A. Elmets. 1989. Inhibition of the high affinity $\mathrm{Fc}$ receptor $(\mathrm{Fc} \gamma \mathrm{RI})$ on human monocytes is highly specific and mediated by the generation of superoxide anions. J. Biol. Chem. 264:11407-11413.

31. Thiele, D. L., M. Kurosaka, and P. E. Lipsky. 1983. Phenotype of the accessory cell necessary for mitogen-stimulated $T$ and $B$ cell responses in human peripheral blood: delineation by its sensitivity to the lysosomotropic agent, L-Leucine-Methyl-Ester. J. Immunol. 131:2282-2290.

32. Walker, C., W. J. Pichler, M. Koponen, W. Donzig, and A. L. DeWeck. 1986. Different effects of IL-2 addition or antibody crosslinking on T-cell subset stimulation by CD3 antibodies. Cell. Immunol. 101:195-203.

33. Geppert, T. D., and P. E. Lipsky. 1987. Accessory cell independent proliferation of human T4 cells stimulated by immobilized monoclonal antibodies to CD3. J. Immunol. 138:1660-1666.

34. Moldwin, R. L., D. W. Lamcki, K. C. Hexold, and F. W. Fitch. 1986. An antigen receptor-driven interleukin 2 -independent pathway for proliferation of murine cytolytic T lymphocyte clones. J. Exp. Med. 163:1566-1582.

35. Tax, W. J. M., F. S. M. Hermes, R. W. Willens, P. J. A. Capel, and R. A. P. Koene. 1984. Fc receptors for monocyte IgG1 on human monocytes: polymorphism and role in antibody induced $\mathrm{T}$ cell proliferation. J. Immunol. 133:1185-1189.
36. Looney, R. J., and G. N. Abraham. 1984. The Fc portion of intact IgG blocks stimulation of human PBMC by anti-T3. J. Immunol. 133:154-156.

37. Looney, R. J., G. N. Abraham, and C. L. Anderson. 1986. Human monocytes and $\mathrm{U} 937$ cells bear two distinct $\mathrm{Fc}$ receptors for IgG. J. Immunol. 136:1641-1647.

38. Guyre, P. M., R. M. Margenelli, and R. Miller. 1983. Recombinant immune interferon increases immunoglobulin G Fc receptors on cultured human mononuclear phagocytes. J. Clin. Invest. 72:393-397.

39. Marlin, S. D., and T. A. Springer. 1987. Purified intercellular adhesion molecule-1 (ICAM-1) is a ligand for lymphocyte function associated antigen-1 (LFA-1) Cell. 51:813-819.

40. Dougherty G. J., S. Murdock, and N. Hogg. 1988. The function of human intercellular adhesion molecule-1 (ICAM-1) in the generation of an immune response. Eur. J. Immunol. 18:35-39.

41. Springer, T. A., M. L. Dustin, T. K. Kishimoto, and S. D. Marlin. 1987. The lymphocyte function-associated LFA-1, CD2, and LFA-3 molecules: cell adhesion receptors of the immune system. Annu. Rev. Immunol. 5:223-252.

42. Altmann D. M., N. Hogg, J. Trowsdale, and D. Wilkinson. 1989. Cotransfection of ICAM-1 and HLA-DR reconstitutes human antigen presenting cell function in mouse $\mathrm{L}$ cells. Nature (Lond.). 338:512-514.

43. Ansel, J. C., T. A. Luger, and I. Green. 1983. The effect of in vitro and in vivo UV irradiation on the production of ETAF activity by human and murine keratinocytes. J. Invest. Dermatol. 81:519-523.

44. Kupper, T. S., A. O. Chua, P. Flood, J. McGuire, and U. Gubler. 1987. Interleukin 1 gene expression in cultured human keratinocytes is augmented by ultraviolet irradiation. J. Clin. Invest. $80: 430-436$.

45. Koide, S. L., K. Inaba, and R. M. Steinman. 1987. Interleukin 1 enhances $\mathrm{T}$-dependent immune responses by amplifying the function of dendritic cells. J. Exp. Med. 165:515-530.

46. Elmets, C. A., K. Larson, G. A. Urda, and B. Schacter. 1987. Inhibition of postbinding target cell lysis of lymphokine-induced enhancement of human natural killer cell activity by in vitro exposure to ultraviolet B radiation. Cell. Immunol. 104:47-58. 